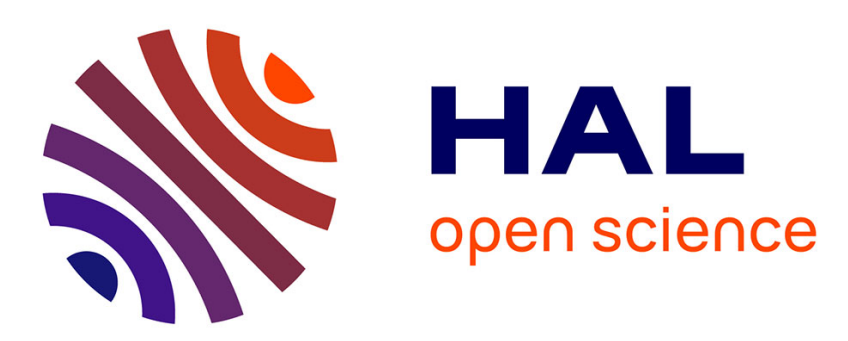

\title{
Monitoring of the discoloration on c-irradiated PE and EVA films to evaluate antioxidant stability
}

Fanny Gaston, Nathalie Dupuy, Sylvain Marque, Didier Gigmes, Samuel

Dorey

\section{- To cite this version:}

Fanny Gaston, Nathalie Dupuy, Sylvain Marque, Didier Gigmes, Samuel Dorey. Monitoring of the discoloration on c-irradiated PE and EVA films to evaluate antioxidant stability. Journal of Applied Polymer Science, 2018, 135 (18), pp.46114. 10.1002/app.46114 . hal-01764643

\section{HAL Id: hal-01764643 \\ https://hal.science/hal-01764643}

Submitted on 13 Apr 2018

HAL is a multi-disciplinary open access archive for the deposit and dissemination of scientific research documents, whether they are published or not. The documents may come from teaching and research institutions in France or abroad, or from public or private research centers.
L'archive ouverte pluridisciplinaire HAL, est destinée au dépôt et à la diffusion de documents scientifiques de niveau recherche, publiés ou non, émanant des établissements d'enseignement et de recherche français ou étrangers, des laboratoires publics ou privés. 


\title{
Monitoring of the discoloration on $\gamma$-irradiated PE and EVA films to evaluate antioxidant stability
}

\author{
Fanny Gaston $\mathbb{1 D}^{1,2,3}$ Nathalie Dupuy, ${ }^{1}$ Sylvain R. A. Marque, ${ }^{2,4}$ Didier Gigmes, $^{2}$ Samuel Dorey $^{3}$ \\ ${ }^{1}$ Aix Marseille University, CNRS, IRD, Avignon Université, IMBE UMR 7263, Marseille, France \\ ${ }^{2}$ Aix Marseille University, CNRS, Institut de Chimie Radicalaire UMR7273, Marseille, France \\ ${ }^{3}$ Sartorius Stedim FMT S.A.S, Z.I. Les Paluds, Aubagne Cedex 13781, France \\ ${ }^{4}$ Vorozhtsov Novosibirsk Institute of organic chemistry, Novosibirsk 630090, Russia \\ Correspondence to: F. Gaston (E-mail: fanny.gaston@sartorius.com) and S. Dorey (E-mail: samuel.dorey@sartorius.com)
}

\begin{abstract}
Irradiated films could provoke unexpected interaction with proteins for instance just after irradiation and not necessarily after 12 months indicating there is no more reactive species. The optical properties of two multilayer films [polyethylene (PE)/ethylene vinyl alcohol (EVOH)/PE and ethylene vinyl acetate (EVA)/EVOH/EVA] after different $\gamma$-irradiation doses is then studied in this work. The investigation on these films, either non-irradiated or $\gamma$-irradiated (up to $270 \mathrm{kGy}$ ), is performed by colorimetry measurement over time (up to 12 months) to assess the generation of new species inside the materials. The color change is directly correlated with absorbed $\gamma$-doses. Over time, the color decreases and goes back to its initial time level. This discoloration evolution could be therefore used as an indication of the completion of the generated species reactions induced by $\gamma$-irradiation.

KEYWORDS: biomedical applications; degradation; spectroscopy

\section{INTRODUCTION}

The use of single-use device in biopharmaceutical and biotechnological industries has become common nowadays. These devices include flexible containers made of multilayer films, which can consist of polyethylene (PE), ethylene vinyl acetate (EVA), and ethylene vinyl alcohol $(\mathrm{EVOH})$. These polymers are used for their flexibility and barrier properties. ${ }^{1}$ Single-use devices are often used to store, ship, freeze, either processing biopharmaceutical media such as buffer, or solutions containing active pharmaceutical ingredients (API). One important feature of these single-use devices is the transparency to check visually the key quality attributes of the biopharmaceutical media. For future use, these devices must be sterilized. $\gamma$-Irradiation is the most widely used sterilization process because of its high penetrating capability. ${ }^{2,3}$ Ionizing radiation effects on polymers have been widely investigated, showing that chemical and physical properties of single-use plastic containers under $\gamma$-rays exposure can undergo changes. These types of changes depend on many factors, such as the type of plastic materials (chemical structure and morphology of polymer), specific additives used inside the plastic, radiation dose, and the irradiation atmosphere. ${ }^{4-16}$ It is well known that the main effect of the interaction of $\gamma$-rays with polymers is the formation of free radicals, whose further evolution can cause scission and/or crosslinking events, ${ }^{17,18}$ and among other things: release of gases, discoloration, changes in mechanical properties and gas permeability, degradation and leaching of polymer additives into solvents, etc. This study is then a part of a global investigation about the impact of the $\gamma$ irradiation on multilayer plastic films. An increase of the oxygen permeability for instance could provoke an oxidation of sensitive proteins leading to a decrease of the product quality and even to health issues. The mechanical properties change could become problematic when it causes trouble to the single use system handling conducting to break and linkage due to a potential increase of the film brittleness. Previous studies have likewise shown that plastic film which is the main part constituting the single use devices can undergo oxidation leading to the creation of carboxylic acids, ketones, and other oxygenated species without structural damage. ${ }^{19-21}$ This oxidation and the color change are inherent to polymers under $\gamma$-irradiation and cannot be avoided, whatever the stabilization package incorporated into the polymers. It is thereof crucial to identify the phenomena responsible of the discoloration and to apprehend the 


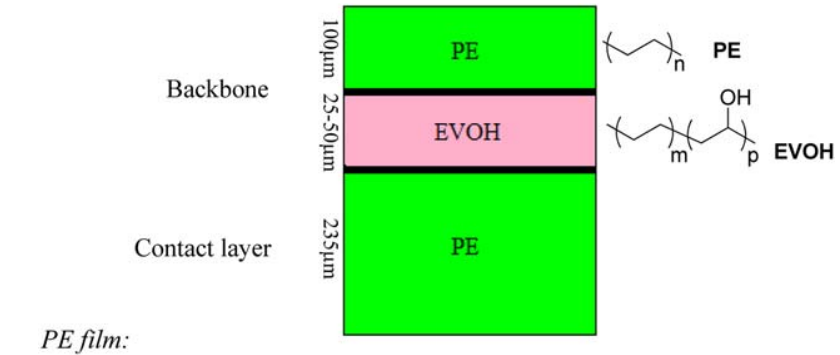

EVA film:

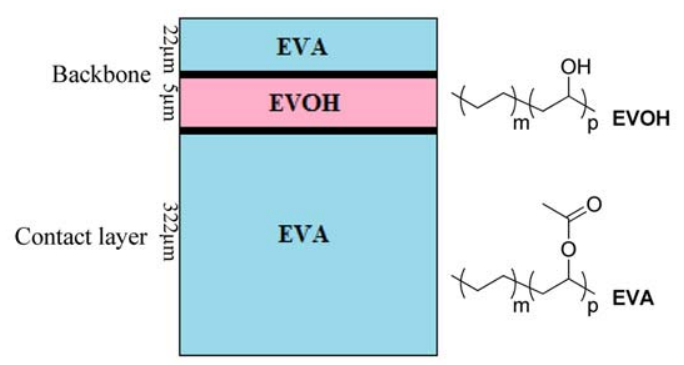

Figure 1. Structure of PE film (top) and EVA film (bottom). [Color figure can be viewed at wileyonlinelibrary.com]

impact that the discoloration root cause(s) can have afterward on the product quality.

The $\gamma$-irradiation of plastic bags can acquire thus undesirable optical properties as a consequence of color formation. This change of the optical property of the plastics could primarily hinder handling properly the single-use devices to check the key quality attributes of the stored media and is secondly a sign that the discoloration of films after $\gamma$-irradiation involves changes inside the polymers. There are developments of chromophore centers either in polymers or in additives. Several authors propose that the discoloration can be attributed to the formation of double bonds conjugated ${ }^{22}$ or the formation of the by-products from hindered phenolic antioxidants (AOs) ${ }^{23,24}$ The phenolic AOs can undergo oxidative transformations to quinoidal products with conjugated $\pi$-electrons. Klemchuck and Horng $^{25,26}$ have shown that the presence of phenolic AOs in polymer contributes to the yellowness in comparison with polymer containing no stabilizer. They have listed the ultraviolet (UV) and visible absorption characteristics of by-products of phenolic AOs. Previous study ${ }^{27}$ has shown that phenolic AO undergoes a cascade of reaction through radical degradation pathway. This study also showed that the some radicals' lifetime could be up to 3 months. The end of the radical lifetime could indicate the end of any additive by-product transformations in the system. It could indicate a state where any interactions between single-use device and media or API are negligible. On the other hand, another series of studies has shown that the creation of double bonds of the film surface constituting mainly the single-use devices is weak. The film is wholly stable under $\gamma$-irradiation. The evolution of the material yellowness could be used as a mean of monitoring primary and secondary AOs transformation into by-products which could evolve overtime into other species. The discoloration evolution could be used to evaluate the by-products reactional scheme and involving radicals and/or chemical rearrangements between species. The migration of the new generated species will be then investigated in another study. Two multilayer films are investigated after $\gamma$ irradiation at several doses, up to $270 \mathrm{kGy}$ to exaggerate and to better emphasize color modifications, and compared with a non-irradiated sample used as reference. In parallel, the natural ageing is evaluated up to 12 months to cover a large range of storage periods in biotechnology applications.

\section{EXPERIMENTAL}

\section{PE Film, EVA Film, and Additives}

The structures of the multilayer film samples are depicted in Figure 1. PE film is composed of PE and EVOH, with a thickness of about $400 \mu \mathrm{m}$. EVA film is composed of EVA and $\mathrm{EVOH}$, with a thickness of $\sim 360 \mu \mathrm{m}$. The different layers of these films contain additives including such as antiblocking agents and $\mathrm{AO}$ (especially phenol, primary AOs, and phosphite, secondary $\mathrm{AOs}^{28-30}$ ) for their stabilization during manufacturing process and during their shelf life. The primary and secondary AOs commonly used in polyolefins stabilization and studied in this article are depicted in Figure 2. The AOs are purchased from Sigma Aldrich (Saint-Quentin-Fallavier, France) and are stored at room temperature. They are used as received.

\section{$\gamma$-Irradiation}

Sheets of PE film and EVA film are packed and wrapped in specific packaging $(\mathrm{PE})$ and irradiated at room temperature in a ${ }^{60} \mathrm{Co} \gamma$-source. The ${ }^{60} \mathrm{Co} \gamma$-source provided a dose rate of $8-13$ $\mathrm{kGy} / \mathrm{h}$ as given by Synergy Health society (Marseille, France) affording doses at $30( \pm 1), 50( \pm 1), 115( \pm 2)$, and $270( \pm 5)$ $\mathrm{kGy}$. A sterilization cycle corresponds $\sim 25 \mathrm{kGy}$. Desired dose is obtained by several sterilization cycles, including a noncontrolled waiting time in non-controlled storage conditions between each cycle. The first analyze is performed on the film samples $\sim 5$ days after $\gamma$-irradiation. AOs are packed in vials and irradiated in the same conditions than film samples but only at $115( \pm 2)$ and $270( \pm 5) \mathrm{kGy}$.

\section{Discoloration Measurement}

The color is measured using a colorimeter BYK spectro guide $45 / 0$. The principle is based on tristimulus measurement in terms of lightness " $L$ " from black to white, " $a$ " from green (-) to red $(+)$, and " $b$ " from blue $(-)$ to yellow $(+)$. The color measurements are taken using a D65 illumination source with an observation interval of $10^{\circ}$. Illuminant D65 is intended to represent average daylight. The spectral range corresponds to 400-700 nm with a resolution of $10 \mathrm{~nm}$. The coding $L, a, b$ of color space has been established in 1976 by the CIE (Commission Internationale de l'Eclairage) to define a color. The quantification of color is discussed by several authors. ${ }^{31,32}$ Colorimetric parameters $L, a, b$, and visible spectra are determined for irradiated and non-irradiated samples. The visible spectra of AOs are also recorded to complete the observations done on visible spectra of film samples. The visible spectra are presented in absorbance. Moreover, this study is led over time; recordings of film discoloration are performed up to 12 months after $\gamma$-irradiation. The measurements are directly performed on three batches of PE film and on three batches of EVA film. For each condition of ageing and $\gamma$-irradiation dose, the non-sterile sample is taken as the reference. 

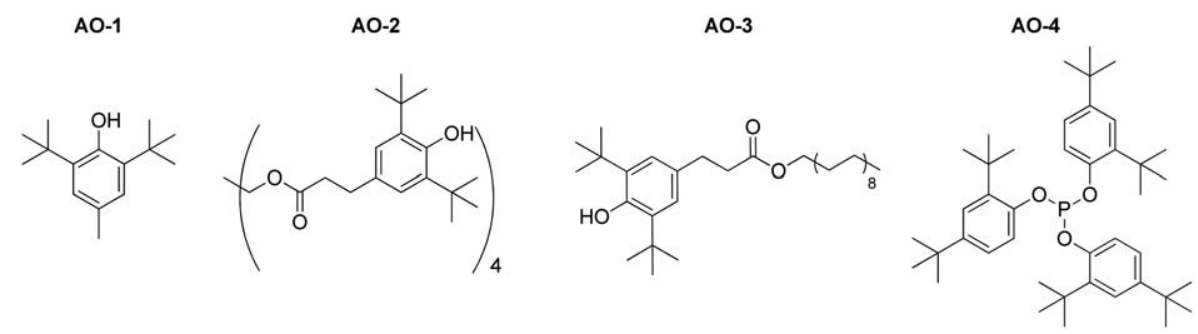

Figure 2. Structure of primary and secondary AOs: AO-1: 2,6-di-tert-butyl-p-cresol, AO-2: pentaerythritol tetrakis (3-(3,5-di-tert-butyl-4-hydroxyphenyl)propionate), AO-3: octadecyl 3-(3,5-di-tert-butyl-4-hydroxyphenyl)propionate, AO-4: tris (2,4-di-tert-butylphenyl)phosphite.

The visible spectra of $\mathrm{AOs}$ in solid form are recorded at $\mathrm{t} 0$, which corresponds at the moment after $\gamma$-irradiation and at two years $(\mathrm{t} 2 \mathrm{y})$ after $\gamma$-irradiation. The AOs are introduced in $2 \mathrm{~mm}$ thickness cell before recording spectra. Thus, the spectra obtained correspond to high concentration of AOs compared to their proportion in films. To ensure good reproducible measurements, the values reported are the average of five experiments given directly by the device.

\section{Principal Component Analysis and Software}

Principal component analysis (PCA) is used here as an exploratory data analysis. $\mathrm{PCA}^{19,20,33}$ is a variable reduction technique used to reduce a larger set of variables into a smaller set of variables called "principal component." The principal components represent the most variance in the original variables. All computations were performed using SIMCA 14.1

\section{Infra-red}

Samples were directly deposited onto the Bruker "Golden Gate" attenuated total reflectance (ATR) accessory provided with a diamond crystal. The spectra for each film sample were recorded from 4000 to $650 \mathrm{~cm}^{-1}$, with $4 \mathrm{~cm}^{-1}$ resolution and 64 scans, on a Thermo Nicolet Avatar spectrometer equipped with a MCT/A detector, an Ever-Glo source, and a KBr/germanium beam splitter. The spectrometer was placed in an airconditioned room at $21^{\circ} \mathrm{C}$. A background scan in air (under the same resolution and scanning conditions as those used for the samples) was carried out before three or five sets of acquisition. The ATR plate was cleaned in situ by scrubbing with an ethanol solution to remove any residual traces of the previous sample. Cleanliness was checked by recording a background spectrum.

\section{RESULTS AND DISCUSSION}

\section{Antioxidants}

As the discoloration of films after $\gamma$-irradiation involves the development of chromophore centers either in polymers or in additives, we have presently studied four phenolic primary and secondary AO involved either in PE or EVA films. The evolution of visible spectra of AOs $\gamma$-irradiated at several doses has been recorded up to 2 years (Figure 4). It could thus afford valuable insights of the event occurring in the multilayer films. The nonirradiated pure AOs exhibit weak absorption in the visible range. AO-1 non-irradiated absorbs more than other AOs $(0.2$ absorbance for AO-1 vs. $\sim 0.15$ absorbance for AO-2, AO-3, and $\mathrm{AO}-4)$. The $\gamma$-irradiation induces a modification of the color for the four AOs (Figure 3). All of them present an increase of the absorption. The AO-1, AO-2, and $\mathrm{AO}-3$ present a main absorption between 500 and $680 \mathrm{~nm}$ and all of them present an absorption in the $400-450 \mathrm{~nm}$ range. This explains the color difference among the four AOs: $\mathrm{AO}-1, \mathrm{AO}-2$, and $\mathrm{AO}-3$ are blue and AO-4 is yellow. The maximal absorption for the four AOs is at $400 \mathrm{~nm}$ letting us to presume that the four AOs absorb in UV. The AO-1 absorptions generated by the $\gamma$-irradiation are constant up to 2 years as shown in Figure 4. The molecules generated from $\mathrm{AO}-1$ after $\gamma$-irradiation are more stable than from the other AOs. The absorptions of the AO-2, AO-3, and AO-4 decrease over time. The AO- 3 and AO-4 absorptions decrease rapidly over time compared to the one of the AO-2. The discoloration of $\mathrm{AOs}$ is due to their conjugated byproducts

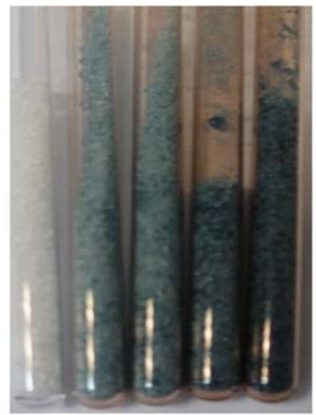

$0 \mathrm{kGy} \rightarrow 270 \mathrm{kGy}$

AO-1

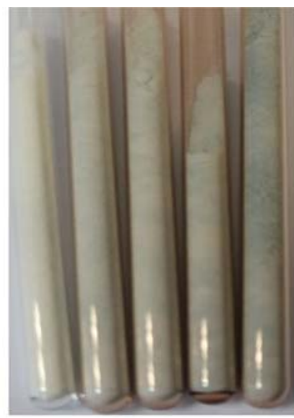

$0 \mathrm{kGy} \rightarrow 270 \mathrm{kGy}$

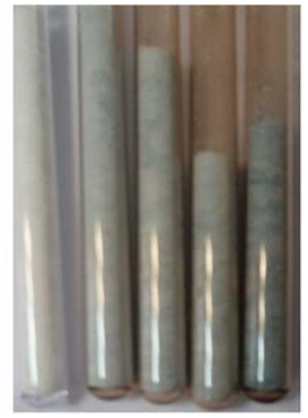

$0 \mathrm{kGy} \rightarrow 270 \mathrm{kGy}$

AO-3

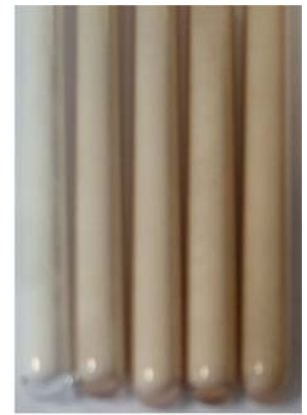

$0 \mathrm{kGy} \rightarrow 270 \mathrm{kGy}$

AO-4

Figure 3. Photographies of non-irradiated and irradiated AOs at $\mathrm{t} 0$. For each $\mathrm{AO}$, the five tubes correspond respectively to samples irradiated at 0 , 30, 50,115 , and $270 \mathrm{kGy}$ (from left to right). [Color figure can be viewed at wileyonlinelibrary.com] 

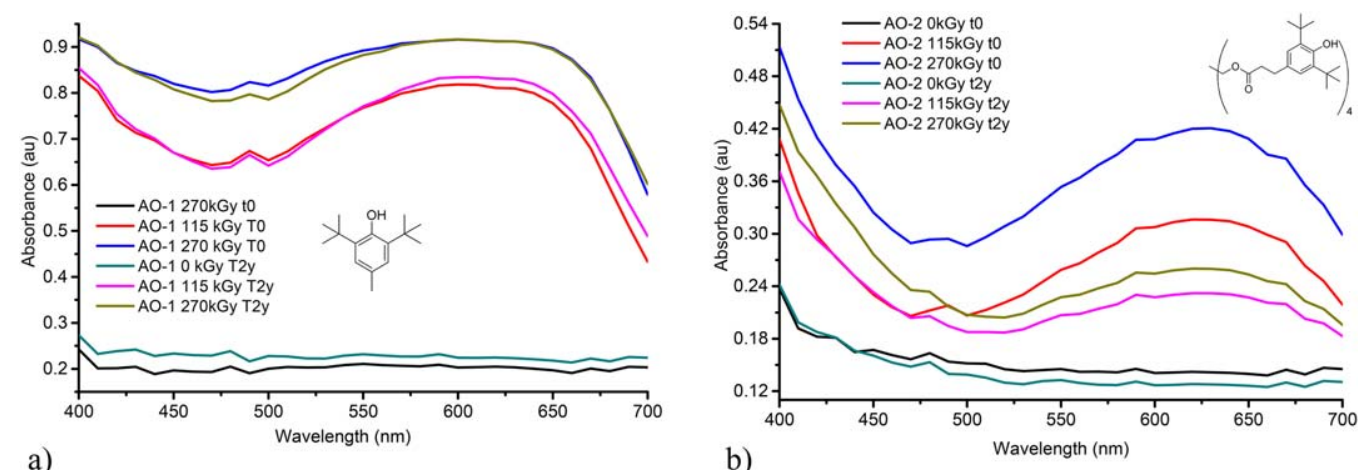

a)

b)
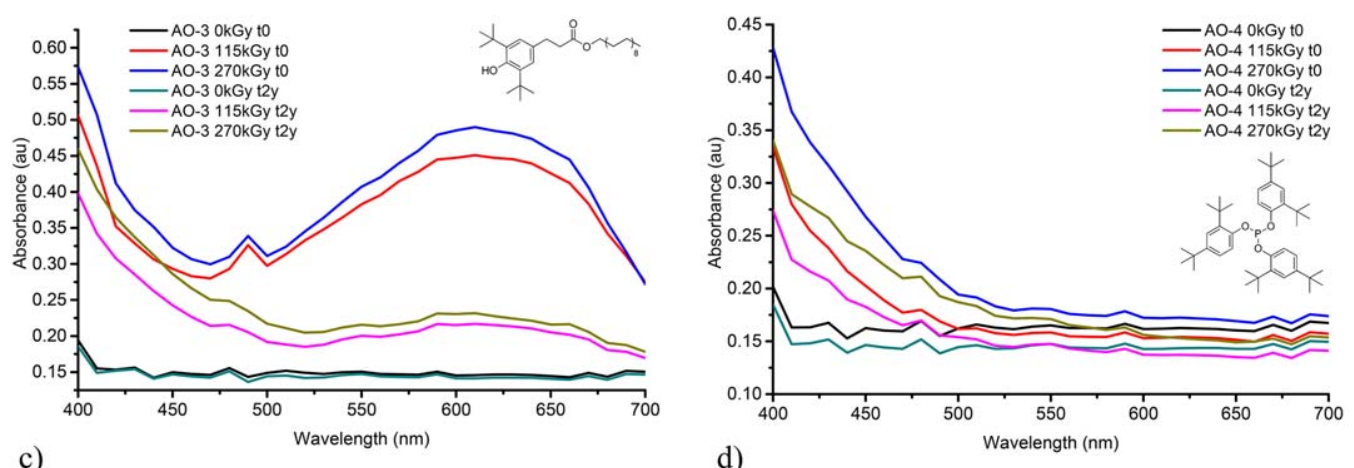

d)

Figure 4. Visible spectra of AOs over time. (a) AO-1, (b) AO-2, (c) AO-3, (d) AO-4. t0 = initial time after $\gamma$-irradiation, t2y=2 years after $\gamma$-irradiation. [Color figure can be viewed at wileyonlinelibrary.com]
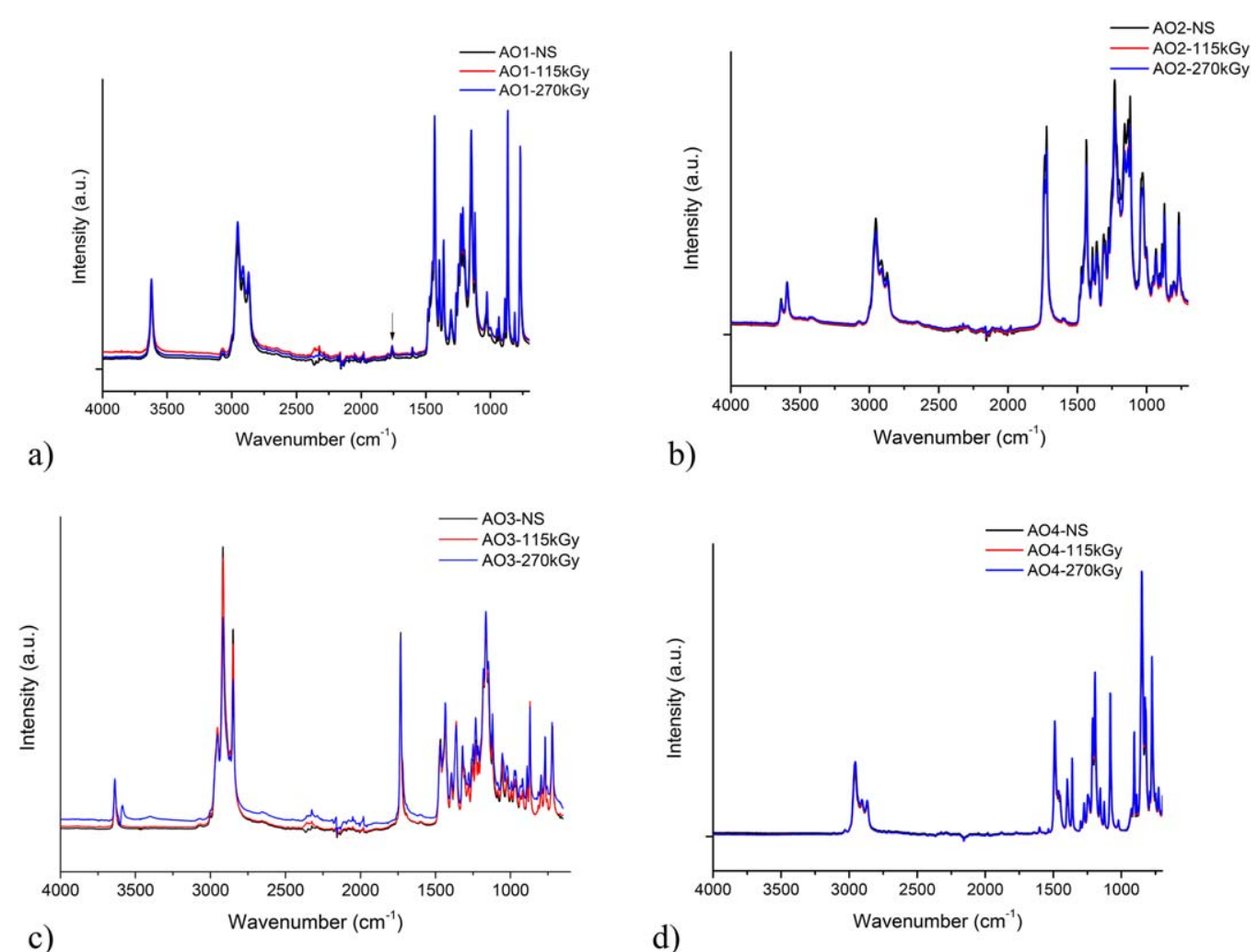

Figure 5. FTIR spectra of AOs gamma irradiated at several doses: (a) AO-1, (b) AO-2, (c) AO-3, (d) AO-4. [Color figure can be viewed at wileyonlinelibrary.com] 


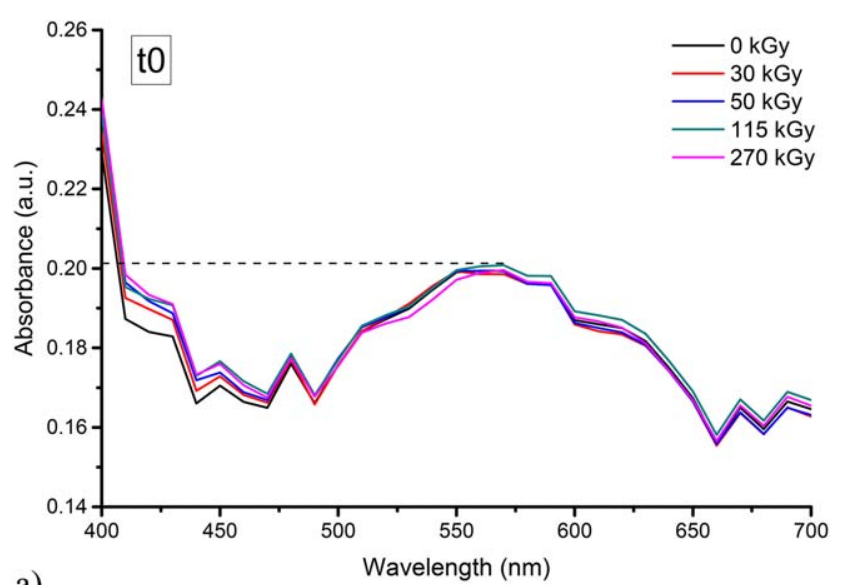

a)

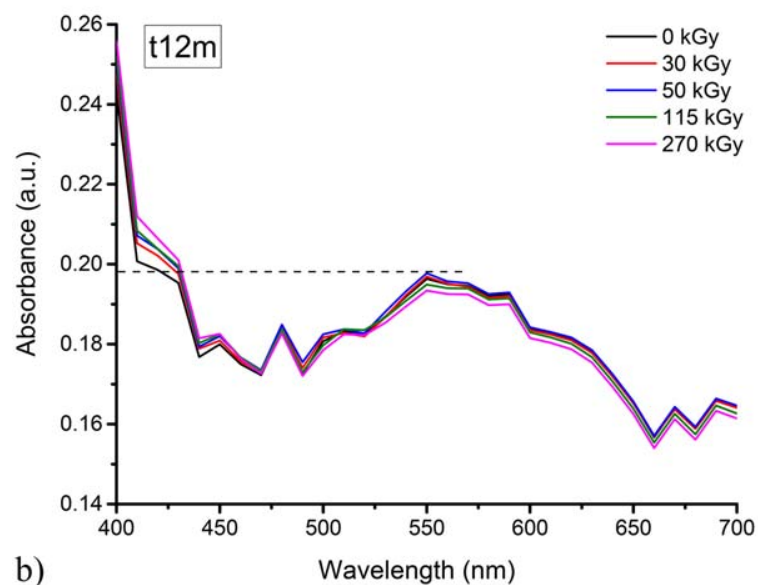

Figure 6. Visible spectra of PE film: (a) at t0 and irradiated at all $\gamma$-doses, (b) at $\mathrm{t} 12$ months at all $\gamma$-doses. [Color figure can be viewed at wileyonlinelibrary.com]

(Supporting Information Figures 1 and 2). ${ }^{26,34}$ The degradation of the AO-4 is not prone to lead colored conjugated byproduct.

These results are in concordance with the monitoring of radi$\mathrm{cals}^{27}$ where the ESR signal was stable for the four AOs up to 1 year. The AO- 1 presented the highest ESR $\left(5 \times 10^{19}\right.$ molecules/ $\mathrm{mg}$ at $270 \mathrm{kGy}$ ) signal in link with the highest absorbance while the AO-4 presented the lowest ESR signal $\left(10^{18}\right.$ radicals $/ \mathrm{mg}$ at $270 \mathrm{kGy}$ ). The spectroscopic study (Figure 5) shows there is no difference between non-irradiated and irradiated AOs indicating that the quantity of transformed molecules is weak and below the sensitivity of this spectroscopic method $(<2 \%)$. In the Fourier transform infrared (FTIR) spectra, there is no apparition or no evolution of the carbonyl band at $1730-1760 \mathrm{~cm}^{-1}$, which is a key moiety in the colored molecules (Supporting Information Figures 1 and 2). The number of colored molecules formed and thereof the corresponding number of radicals at the origin of their formation is weak in accordance with the ESR signal.

\section{PE Film}

The visible spectra of PE film at various $\gamma$-irradiation doses up to 12 months are displayed in Figure 6. The intensity of the bands 525-625 nm in Figure 4(b) decreases over time compared to the same bands recording at t0 shown in Figure 4(a). At t0 the non-sterile film (i.e., $0 \mathrm{kGy}$ ) is the sample presenting the lowest absorption, especially in area $400-475 \mathrm{~nm}$, so the less colored film. In order to emphasize the evolution of color, a PCA is performed on the visible spectra (400-700 $\mathrm{nm}$ range) recorded at $0,30,50,115$, and $270 \mathrm{kGy}$ and over time.

The PCA performed on visible spectra (Figure 7) shows that the two first components explain $89 \%$ of the data variation. The first component (66\%) (Figure 7) could be associated to $\gamma$ irradiation. The spectra obtained for high $\gamma$-doses are negatively projected since the ones corresponding to the low $\gamma$-doses are positively projected. One can see on the second component (23\%) [Supporting Information Figure 3(a)] an effect of the natural ageing, essentially for short times, with a major observation that the effect does not seem to be continuous in time. This evolution is respected whatever is the $\gamma$-irradiation dose but not equivalent among the different $\gamma$-irradiation doses. The loading of PC1 [Supporting Information Figure 3(c)] shows that bands between 400 and $500 \mathrm{~nm}$ are more intense for the old ageing times. The scores plot representing the batches [Supporting Information Figure 3(b)] displays that there is no influence of batch. All batches behave in the same way. This area corresponds to violet-blue zone, which corresponds to the first absorption of AOs. For the AOs, the decrease of the absorption in 400-500 $\mathrm{nm}$ area is the lowest. As AO-1 absorption does not decrease over time and as the whole film absorption decreases over time, thus the AO-1 concentration is too weak to be detected. Conjugated bonds on the polymer backbone are not observed in agreement with previous study. ${ }^{20}$ The changes observed under $\gamma$-irradiation by infrared spectroscopy concern the carboxylic acids and non-conjugated unsaturated compounds on the film surface. If there is a migration of byproducts from the core to the surface, then it is in trace amounts and therefore not visible by ATR-FTIR. According to Electron Spin Resonance (ESR) study, ${ }^{27}$ radicals were observed during 3 months in PE-film which corresponds to the disappearance of the color component $(500-600 \mathrm{~nm})$. We can see here that there is a link between the end of the shelf-life of the radical, the end of the phenolic by-product transformation, and the end of the discoloration evolution. It could give thus an indication that interaction between single-use devices and

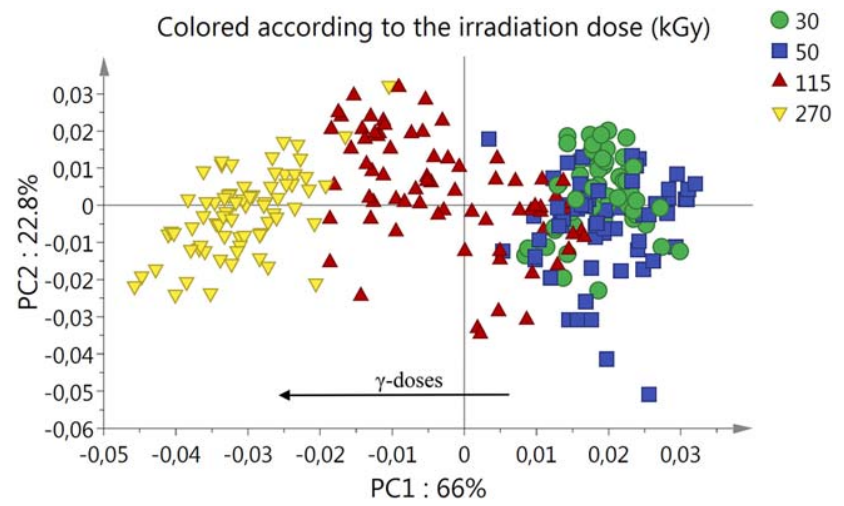

Figure 7. PCA of visible spectra of PE film: Scores plot with $\gamma$-dose labels (in kGy). [Color figure can be viewed at wileyonlinelibrary.com] 

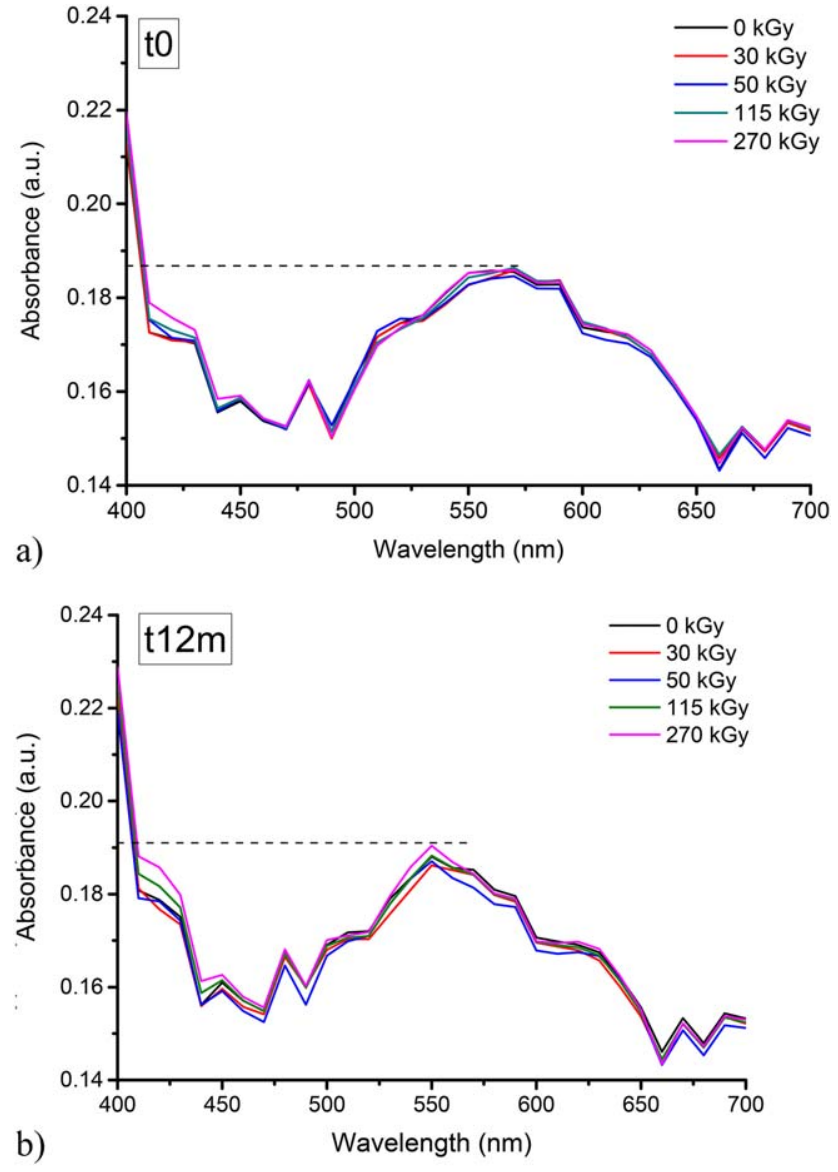

Figure 8. Visible spectra of EVA film: (a) at t0 and irradiated at all $\gamma$ doses, (b) at t12months at all $\gamma$-doses. [Color figure can be viewed at wileyonlinelibrary.com]

sensitive API could be minimized when there is a stabilization of the discoloration that is to say between 100 and 150 days.

\section{EVA Film}

The visible spectra of EVA film at various $\gamma$-irradiation doses are represented in Figure 6. There is no change in the band intensity over time [Figure $6(\mathrm{a}, \mathrm{b})$ ]. The spectra obtained at the same time at different doses are similar to naked eye [Figure $4(\mathrm{a}, \mathrm{b})]$. In order to emphasize the evolution of color, a PCA is performed on the visible spectra (400-700 nm range) recorded at $0,30,50,115$, and $270 \mathrm{kGy}$ and over time.

The PCA performed on visible spectra shows different groups organized according to the $\gamma$-doses (Figure 9) under the first component. The two first components explain $75 \%$ of the variance. Concerning the $\gamma$-doses, there is an organization from right to the left ranking the samples according to the absorbed dose (Figure 9): the samples irradiated at high doses are placed at left and the samples irradiated at low doses and nonirradiated are placed at right. Regarding the corresponding loading [Supporting Information Figure 4(c), component 1], the samples irradiated at high $\gamma$-doses present an increase of the absorption in blue zone (400-440 $\mathrm{nm}$ and $490 \mathrm{~nm}$ ). This evolution is in good agreement with the evolution of the AO-1, AO-

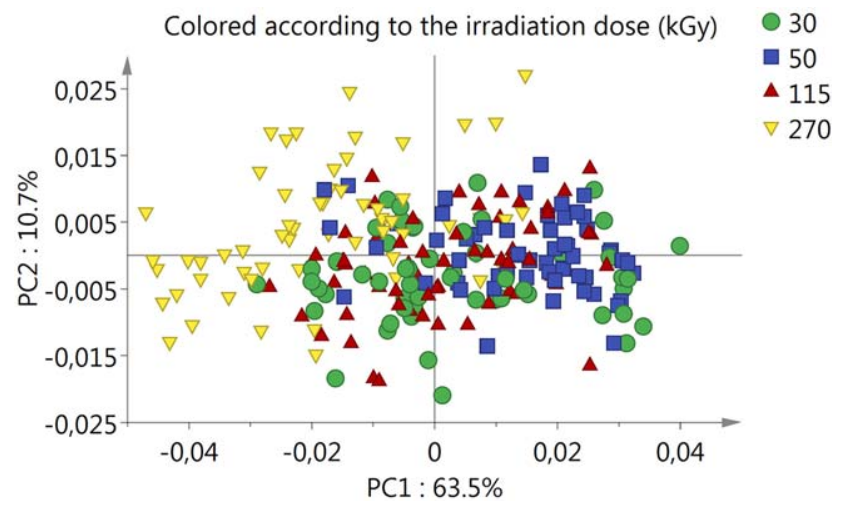

Figure 9. PCA of visible spectra of EVA film: Scores plot of PCA with $\gamma$ dose labels. [Color figure can be viewed at wileyonlinelibrary.com]

2, AO-3, and AO-4. There is no ageing effect [Supporting Information Figure $4(\mathrm{a})$ ] or batch effect [Supporting Information Figure 4(b)]. Conjugated bonds on the polymer backbone are not observed in accordance with a previous study. ${ }^{19}$ Through infrared spectroscopy, no structural change is observed on EVAfilm ${ }^{19}$ and there is not ESR signal whatever the $\gamma$-doses and the ageing time.

\section{Monitoring of the AO Behavior After $\gamma$-Irradiation in Films}

A typical stabilization package for polyolefin will usually consist of a phenol, a phosphite, and an antacid/slip agent (zinc stearate, calcium stearate, oleamide, or erucamide, etc.). ${ }^{35}$ Many additives will thus degrade into by-products contributing to discoloration. $^{26,34,36}$ We will monitor the AO behavior after $\gamma$ irradiation through the discoloration in films. The yellowing index (YI) over time for the PE film is represented in Figure 10. For a fixed due date, the YI increases with the $\gamma$-doses. The YI decreases over time until reaching a plateau (steady state) after the 5th month. Just after $\gamma$-irradiation the film samples have a color change, with a yellowing trend. It decreases during four months and then forms a plateau. These observations mean that there are groups produced during $\gamma$-irradiation, which are responsible for the color change. These groups are probably conjugated systems. Once the discoloration reaches the plateau,

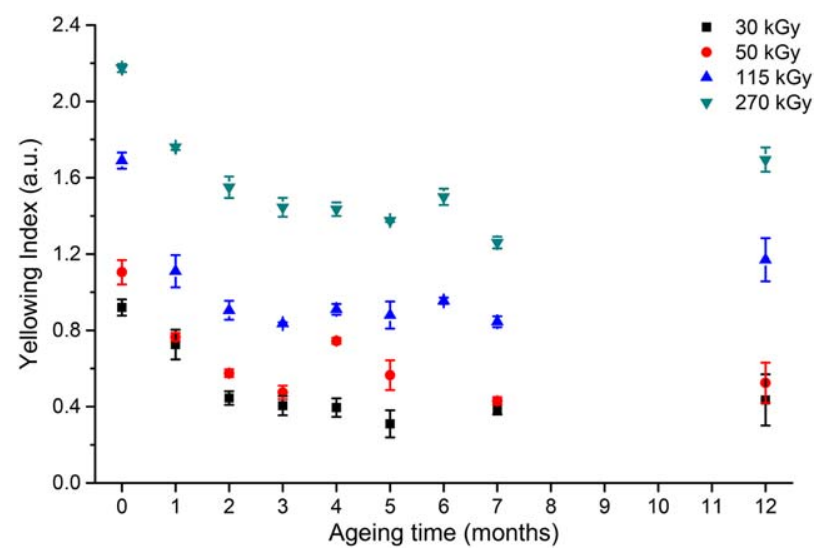

Figure 10. Evolution of YI of the PE film over time and $\gamma$-irradiated at several doses. [Color figure can be viewed at wileyonlinelibrary.com] 

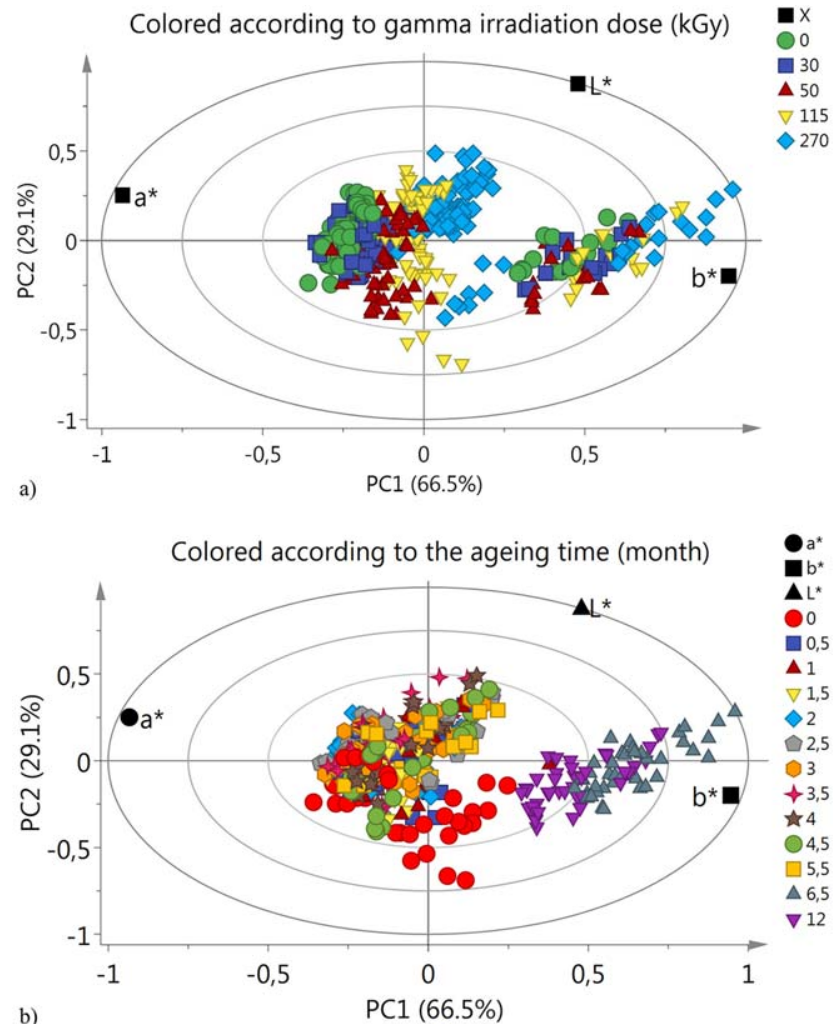

Figure 11. PCA and correlation loading of $L, a, b$ values on PE film. Variable weight is $1 /$ standard deviation. (a) With $\gamma$-doses labels, (b) with ageing labels FILM. Ellipses represent respectively 50\%, 75\%, 100\% of the correlation. [Color figure can be viewed at wileyonlinelibrary.com]

it would mean that all reactive species such as radicals and peroxides have disappeared.

Another way of monitoring the yellowing evolution shown in Figure 10 in films is possible by performing a PCA directly on $L, a, b$ values (Figure 11 ) as the YI is calculated from these $L, a$, $b$ values.

Figure 11 represents the correlation loading according with $\gamma$ doses labels or ageing labels. The two first components explain $96 \%$ of the variance in the dataset. The $a$ and $b$ variables are anti-correlated, the $b$ and $L$, and the $a$ and $L$ are almost noncorrelated. The variable $b$ is essentially correlated with old ageing $(\mathrm{t} 7 \mathrm{~m}$ and $\mathrm{t} 12 \mathrm{~m})$. We can remark that the $\mathrm{t} 12 \mathrm{~m}$ group gets closer to $\mathrm{t} 0$ : there is a reversion over time. This means that after some time, the groups responsible for color change are degraded into groups not colored.

The visible spectra of AOs (Figure 4) can help explain some observations done with the PCA in Figure 11. From the visible spectra of AOs, they absorb in the 400 and $500 \mathrm{~nm}$ zone, as film samples do. It means that the results of PCA depicted in Figure 11 are correlated with the irradiated $\mathrm{AO}$ molecules responsible for color change. The absorbance intensity decreases over time for $\mathrm{AO}-2, \mathrm{AO}-3$, and AO-4. Only the absorbance intensity of AO-1 stays stable over time. The molecules generated from AO- 1 after $\gamma$-irradiation are more stable than from the other AOs. The transformation of radical scavenging

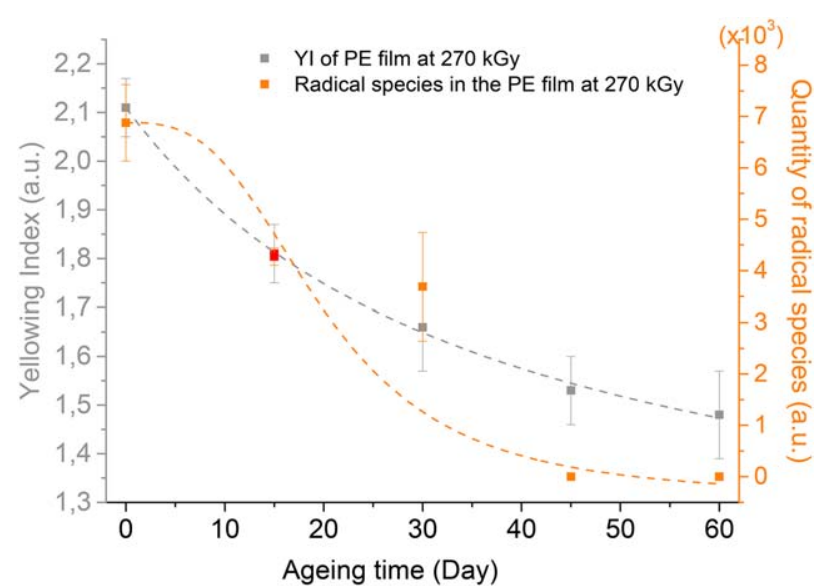

Figure 12. Overtime evolution of the discoloration evaluated through the YI calculated from $L, a, b$ measurements in parallel to the radical species content in the PE film $\gamma$-irradiated at $270 \mathrm{kGy}$. [Color figure can be viewed at wileyonlinelibrary.com]

compounds is then finished. The steadiness of the discoloration is as well in line with the annihilation of the radical ${ }^{27}$ present in the material followed by ESR (Figure 12).

The YI for the EVA film over time is represented in Figure 13. As for the PE film, the YI increases with the $\gamma$-doses for a fixed due date. There is an important standard deviation due to the non-smooth surface of this film.

Figure 14 represents the correlation loading according to ageing labels. The $a$ and $b$ variables are anti-correlated, the $b$ and $L$, and the $a$ and $L$ are almost non-correlated. As for the PE film, the variable $b$ is correlated with old ageing ( $\mathrm{t} 5 \mathrm{~m}, \mathrm{t} 6 \mathrm{~m}$ and $\mathrm{t} 7 \mathrm{~m}$ ), except the $\mathrm{t} 12 \mathrm{~m}$ group. There is a reversion over time indicating that the yellowing discoloration is not a permanent state after the $\gamma$ irradiation. The $\gamma$-irradiation induced modifications in the EVAfilm progress non-linearly with time which could be due to the formation and transformation of colored species, in accordance with previous study ${ }^{21}$ where modification were monitored with spectroscopic tools. Monitoring the discoloration of films through the YI is therefore a hint to apprehend the end of the AO transformation pathway.

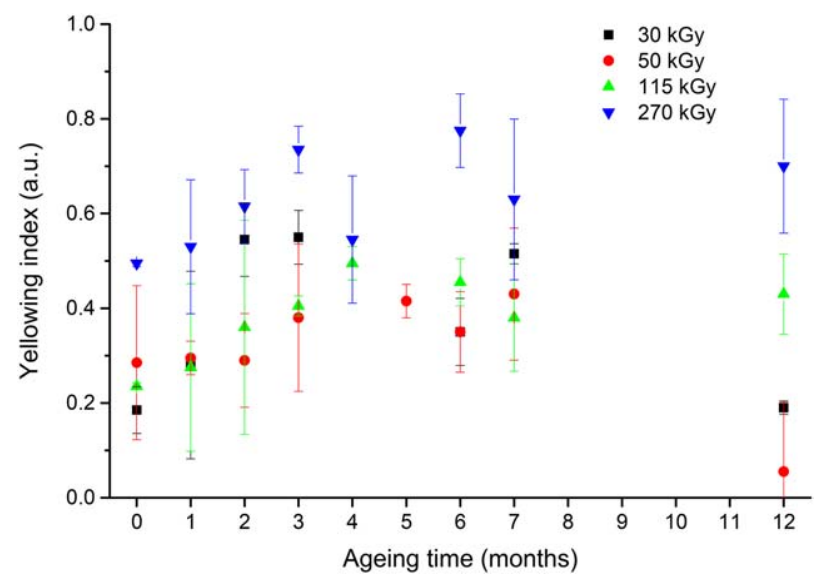

Figure 13. Evolution of YI of the EVA film over time and $\gamma$-irradiated at several doses. [Color figure can be viewed at wileyonlinelibrary.com] 


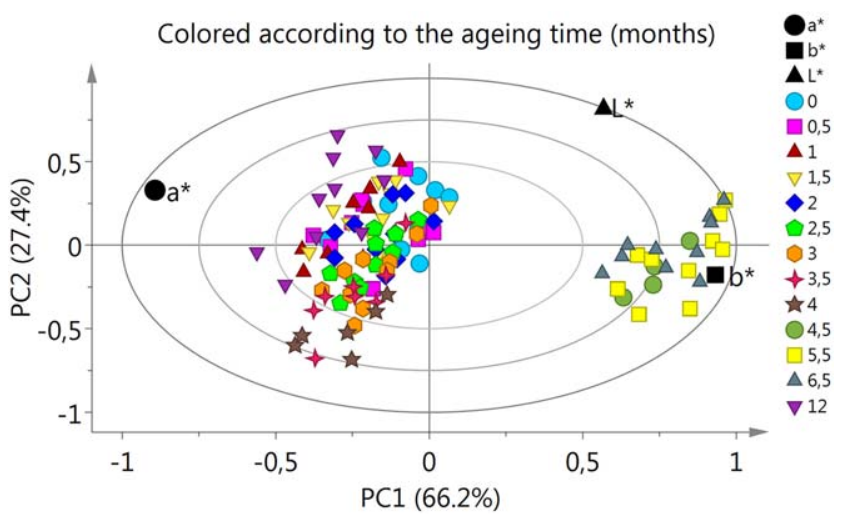

Figure 14. PCA and correlation loading of $L, a, b$ values with ageing labels on EVA-film. Variable weight is 1/standard deviation. Ellipses represent respectively $50 \%, 75 \%, 100 \%$ of the correlation. [Color figure can be viewed at wileyonlinelibrary.com]

\section{CONCLUSIONS}

This study highlighted the color change occurring on two $\gamma$ irradiated multilayer films followed over time. Globally, the films and additives are impacted by the $\gamma$-irradiation. This change is mainly correlated with the $\gamma$-dose and the ageing slightly influences the film color change. However, this change is not proportional over time and shows a trend to come back to the initial state. These observations mean that during $\gamma$-irradiation compounds having chromophore groups are mainly due to the generation of $\mathrm{AO}$ byproducts. We did not observe conjugated bonds on the polymer backbone. These observations can be made whatever the film batch studied. The chromophore compounds are not stable over time and are degraded into new compounds without powerful chromophore groups. This could indicate the end of radical scavenging species transformation inside the films. The discoloration change and evolution could be thus a method to monitor the evolution of the AOs and their by-products revealing then the presence of reactive species such as radicals and peroxides.

\section{REFERENCES}

1. Byun, Y. J.; Hong, S. I.; Kim, K. B.; Jeon, D. H.; Kim, J. M.; Whiteside, W. S.; Park, H. J. Radiat. Phys. Chem. 2007, 76, 974.

2. Clough, R. L. Nucl. Instrum. Methods B 2001, 185, 8.

3. Chuaqui-Offermanns, N. Int. J. Radiat. Appl. Instrum. Part C: Radiat. Phys. Chem. 1989, 34, 1005.

4. Krupa, I.; Luyt, A. S. Polym. Degrad. Stab. 2001, 72, 505.

5. Brody, A. L.; Marsh, K. S. The Wiley Encyclopaedia of Packaging Technology, 2nd ed.; Wiley: New York, 1997.

6. Buchalla, R.; Schuttler, C.; Bogl, K. W. J. Food Prot. 1993, 56, 991.

7. Buchalla, R.; Schuttler, C.; Bogl, K. W. J. Food Prot. 1993, 56, 998.

8. Buchalla, R.; Boess, C.; Bögl, K. W. Radiat. Phys. Chem. 1999, 56, 353.

9. Deschenes, L.; Arbour, A.; Brunet, F.; Court, M. A.; Doyon, G. J.; Fortin, J.; Rodrigue, N. Radiat. Phys. Chem. 1995, 46, 805.
10. Dole, M. The Radiation Chemistry of Macromolecules; Academic Press: New York, 1972; Vols. I and II.

11. Goldman, M.; Gronsky, R.; Ranganathan, R.; Pruitt, L. Polymer 1996, 37, 2909.

12. Goulas, A. E.; Kontominas, M. G. Z. Lebensm. Unters. Forsch. 1996, 202, 250.

13. Goulas, A. E.; Kokkinos, A.; Kontominas, M. G. Z. Lebensm. Unters. Forsch. 1995, 201, 74.

14. Goulas, A. E.; Riganakos, K. A.; Ehlermann, D. A. E.; Demertzis, P. G.; Kontominas, M. G. J. Food Prot. 1998, 61, 720.

15. Goulas, A. E.; Riganakos, K. A.; Badeka, A.; Kontominas, M. G. Food Addit. Contam. 2002, 19, 1190.

16. Riganakos, K. A.; Koller, W. D.; Ehlermann, D. A. E.; Bauer, B.; Kontominas, M. G. Radiat. Phys. Chem. 1999, 54, 527.

17. Jeon, D. H.; Lee, K. H.; Park, H. J. Radiat. Phys. Chem. 2004, 71, 1059.

18. Park, G. Y.; Cho, S. Y.; Jeon, D. H.; Kwak, I. S.; Lee, K. H.; Park, H. J. Radiat. Phys. Chem. 2006, 75, 1055.

19. Gaston, F.; Dupuy, N.; Marque, S. R. A.; Barbaroux, M.; Dorey, S. Polym. Degrad. Stab. 2016, 129, 19.

20. Gaston, F.; Dupuy, N.; Marque, S. R. A.; Barbaroux, M.; Dorey, S. Radiat. Phys. Chem. 2016, 125, 115.

21. Gaston, F.; Dupuy, N.; Marque, S. R. A.; Barbaroux, M.; Dorey, S. Anal. Chim. Acta 2017, 981, 11.

22. Moura, E. A. B.; Ortiz, A. V.; Wiebeck, H.; Paula, A. B. A.; Silva, A. L. A.; Silva, L. G. A. Radiat. Phys. Chem. 2004, 71, 199.

23. Goulas, A. E.; Riganakos, K. A.; Kontominas, M. G. Radiat. Phys. Chem. 2004, 69, 411.

24. Yachigo, S.; Kojima, F.; Sasaki, M.; Ida, K.; Tanaka, S.; Inoue, K. Polym. Degrad. Stab. 1992, 37, 107.

25. Klemchuk, P. P. Radiat. Phys. Chem. 1993, 41, 165.

26. Klemchuk, P. P.; Horng, P.-L. Polym. Degrad. Stab. 1991, 34, 333.

27. Audran, G.; Dorey, S.; Dupuy, N.; Gaston, F.; Marque, S. R. A. Polym. Degrad. Stab. 2015, 122, 169.

28. Jeon, D. H.; Park, G. Y.; Kwak, I. S.; Lee, K. H.; Park, H. J. LWT 2007, 40, 151.

29. Bourges, F.; Bureau, G.; Dumonceau, J.; Pascat, B. Packag. Technol. Sci. 1992, 5, 205.

30. Pospisil, J. Polym. Degrad. Stab. 1993, 40, 217.

31. Mortimer, R. J.; Varley, T. S. Displays 2011, 32, 35.

32. Korifi, R.; Le Dreau, Y.; Antinelli, J.-F.; Valls, R.; Dupuy, N. Talanta 2013, 104, 58.

33. Martens, H.; Naes, T. Multivariative Calibration; Wiley: New York, 1989.

34. Vulic, I.; Vitarelli, G.; Zenner, J. M. Polym. Degrad. Stab. 2002, 78, 27.

35. Pahl, I.; Dorey, S.; Barbaroux, M.; Lagrange, B.; Frankl, H. PDA J. Pharm. Sci. Technol. 2014, 68, 456.

36. Allen, N. S.; Enriquez, L. J.; Edge, M.; Liauw, C. M.; Parrondo, A.; Fontan, E. J. Vinyl Addit. Technol. 2001, 7, 110. 